IV.

\title{
Beschreibung des Centralnervensystems eines 6tägigen, syphilitischen Kindes mit unentwickel- tem Grosshirn bei ausgebildetem Schädel, mit Asymmetrie des Kleinhirns sowie anderer IIirn- theile und mit Aplasie der Nebenmieren.
}

\author{
Von \\ Dr. Georg Ilberg,

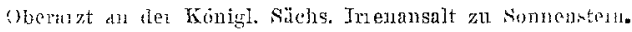

(Hierzu Tafel V.)

Die 24jührige Dienstmagd Agnes Wo. aus R., von der nicht bekannt ist, dass sie in irgend einer Weise hereditär belastet ist, gebar am 17. Decomber 1895 in der Königl. Frauenklinik zu Dresden ein Kind, dessen Gehirn und Rückenmark in Folgendem beschrieben werden sollen.

Die Wo. war seit den 14. Lebensjahr menstruirt, die Regel erfolgte 4wöchentlich; war stark und dauerte 4-6 Tage. 1893 hatte sie zum ersten. Nal geboren, das Kind war ausgetragen, wurde mit der Zange entwickelt, war klein und starb nach 6 Wochen an Schwäcbe. Das in Frage kommende Kind war das zweite. Seine Geburt erfolgte spontan, obwohl das Becken der Muttex mässig verengt war, indem seine Conjugata diagonalis nur $101 / 2$, seine Conjugata rera $81 / 2 \mathrm{~cm}$ maass. Die Mutter war eine schwächliche Person, bei der Zeichen von Lues nicht nachzureisen waren. Das Kind befand sich bei der Geburt in Schädellage IA. Aus dem mir gefälligst zur Verfügung gestellten Journal der Königl. Frauenklinik ist zu entnehmen: Das Neugeborene bewegl sich erst nach Anwendung von Hautretzen, athmet oberflächlich, ist indolent. reagirt schwach, schreit mit leerer Stimme, sieht stark cyanotisch aus. Keine Kopfgeschwulst. An den Schultern emphysematöses Knistern (Fractur?). Länge $50 \mathrm{~cm}$, Gewicht $3320 \mathrm{gr}$. Schulterndurehmesser $11^{1} / 2$ (normal 12), Umfang 37 , Brustdurchmesser $71 / 2$, Umfang 33 . Hüftenbreite $9^{1} / 2$ (normal $9,8 \mathrm{~cm}$ ). Kopfdurchmesser: gerader 10 (normal 11,6-12), senkrechter 9 (normal 9), querer grosser $81 / 2$ (normal 9,25 ), lileiner $71 / 2$ (normal 8 ), schräger $121 / 2$ (nor- 
mal 13), Kopfurfang grösster 37 (normal 36), kloinster 31 (normal 32), occipito-frontaler 321/2 (normal 33-34 cm). Der Fruchtkuchen wog $550 \mathrm{gr}$, war $19 \mathrm{~cm}$ lang, 17 breit, $1 \frac{1}{2}$ dick. Die Nabelschnur hatte eine Länge von 55, eine Dicke von $1 \mathrm{~cm}$. Eihäute vollständig. Fruchtwasser reichlich und von klarer Beschaffenheit. - Nach der Geburt wurden Hautreize angewendet, das Kind wurde erst $1 / 2$ stündlich, dann 3 stündlich gebadet un din Watte eingepackt. Am 18. December: Athmung besser. Realtion auf Hautreize noch inmer abgeschwächt. Gewicht 3280 gr. Cyanotisch, fühlt sich lrühl an, schreit fast nicht. Die Stirnbeine bilden vorne einen Kiel. Geringe Nahrungsaufnahme. Wärmewanne. 19. December: Trinkt etwas besser, sonst wie gestern. $3230 \mathrm{gr}$. 20. December: Zustand unverändert. Die Milch muss dem Kinde eingeflösst werden. Dasselbe nimmt sehr wenig zu sich. $3190 \mathrm{gr}$. 21. December: Der linke Arm wird fest an den Leib gehalten. Bei passiven Abduktionen desselken grosser Widerstand und geringe Schmerzensäusserungen. Bei Druck auf die linke Clavikel fühlt man deutliches Knistern. Starker Icterus. Stuhl stark übelriechend. Flasche, Hafermehl. 3130 gr. 22. December: Viel apathischer als vorher, reagirt auf Hautreize gar nicht. Nabelschnur ist abgefallen. $3090 \mathrm{gr}$. 23. December: Apathie noch grösser als gestern. Um 1 Uhr mittags Exitus lethalis. 3070 gr.

Die Section wurde am 24. December 1895 von Herrn Medicinalrath Dr. Schmorl im pathologischen Institut des Stadtkrankenhauses zu Dresden ausgefuihrt. Das Sectionsprotokoll enthält Folgendes: Körperlänge $51 \mathrm{~cm}$. Leichengewicht $3050 \mathrm{gr}$. Querer Durchmesser des Kopfes 8,5, langer Durchmesser 10,5, schräger 12, Kopfumfang 311, Schulterbreite 13,25, Brustumfang 32 , Hüftbreite $9,5 \mathrm{~cm}$. Haut gelb gefärbt, im Gesicht bläulichroth. Haare $2 \mathrm{~cm}$ lang. Ohrknorpel fest. Nägel hart, die Fingerkupje überragend. Epiphysenlinie intact. Knochenlsern in unterer Femoralepipliyse $7 \mathrm{~mm}$. Muskeln gat entwickelt. Linsengrosser Blutaustritt am linken Sternum, etwas grösserer am linken Kieferwinkel (theils in der Muskulatur des Mundbodens, theils unter dem. Periost des Kiefers). Weiche Kopfbedeckung sehr blutreich; uuter dem Periost Blutaustritte. Schädel hart. Bei Eröffnung der Schädelhöhle entleert sich eine grössere Menge klarer Flüssigkeit. In der Schädelhöhle findet sich kein Gehirn, nur am Eingang zur Medulla oblongata liegt ein etwa fingergliedgrosser Rest weisser Hirnsubstanz. Herz: Unter dem Epicard reichliche Blutaustritte, Endocard des rechten Ventriliels deutlich ikterisch. Rachenschleimhaut und Plicae ary-epiglotticae ödematös. Halslymphdrüsen leicht geschwollen und geröthet. Beide Schilddrüsenlappen sehr gross, derb. Aus den Bronchien beider Lungen quillt trüber Schleim. Schleimhant stark injicirt. Bronchialdrüsen etwas geschwollen und geröthet. Milz: 25 gr, dunkelroth, mässig fest, Pulpa weich, Schnittfläche vorquellend. Magen: Stark aufgetrieben, fasthorizontal. Unt. Leberrand: 2 Finger breit unter dem Rippenbogen. Lymphdrüsen des retroperitonealen Gewebes sehr stark gallig gefärbt. Die rechte Nebenniere sitzt als ausserordentlich kleiner, flacher Körper der Unterfläche des Zwerchfells auf, ist kaum $7 \mathrm{~mm}$ ] ang, $5 \mathrm{~mm}$ breit, $1 \mathrm{~mm}$ dick. Rinde und Mark sind gut zo unterscheiden. Die linke Nebenniere ist von derselben Grosse wie 
die rechte, sie weist in Imen, besonders an der Stelle der Marksubstanz einen ausgedehnteu Blulerguss auf. Der Magen enthält zähen Schleim, ist intensir gerothet und stark gesebwollen. An der Cardia befinden sich 2 halblinsengrosse Geschwüre mit zackigem Riand, gelbem Grund und stark geröthetem Saum. Ausserdem sind zahlreiche feinste, gelbweisse Knötchen za bemexken, die sich hart anfühlen nnd meist längs der Gefässe angeordnet sind. Dünndarm: Schleimiger Inhalt. Schleimhaut stark geschwollen und diffus gerëöthot. Der Inhalt sehr stark übelriechend. Dickdarm: Schleimhaut intensir geröthet, geschrollen, von streifenfürmigen Blutungen ilurchsetzt; Follikel vergrössert, in obcren Theil mit gelbgefärbtem Inhall erfuilt. Leber: Consistenz fest. Oberfliche glat, bräunlich grau. Juf ler Nitte des rechten Jappens befindet sich eine tiefe, strahlige Narbc. Das Gewebe ist dorl, auf der Schnittfläche grünlichbraun, fein böckerig. Das periportale Bindegewebe ist vermehrt, besonders im linken Lapnen, wo die leber ein fouersteinfarbrges Ansehen hat. Galle zäh. Das Gewebe an der Iarnblase ist sehr üßematös. Farn trüb. Schleimhaut geschwollen, ron Blutaustritten durchsotzt. Aus der Schoide quillt roichlicher, gelbweisser, schleimiger Eiter nehen glasigeu. Schlem. Schleimhant stark aufrelockcr. I Iabia majora et minora: Oedenatös, tief blauroth vertärbt.

Herr Medicinalrath Dr. Schmorl hatte die grosse Güte, mir das Centralnerrensystem des Kindes mit dem Kop desselben zur weiteren Untersuchang zu ùbergeben.

Fom Gesicht ist zu berichten, dass Fase, Murd, Gaumen ohne Besonderheiten, speciell auch ohne Asymmetrie.sind, dass die Ohren Degenerationszeichen aufweisen. Die Augen sind wohlgebildet, die Pupillarmembran fehlt. llas Küpfchen ist behaart. Kurze hellbraune Hanre gohen bis $21 / 2 \mathrm{~cm}$ über der Yasentrurzel und $1 \mathrm{~cm}$ über den Augenbrauen tief in die Stim hinein.

Die gegenüberliegenden Seiten der grossen Fontanelle sind $14 \mathrm{~mm}$ ron einander entfernt. Die Knochen des Stimbeins and des Seitenwandbeins haben beiderseits eine Dicke von $1-1 \frac{1}{2} \mathrm{~mm}$, das Hinterhauptbein ist in der Pfeillinie ziemlich $2 \mathrm{~mm}$ dick. Die hintere Fontanelle ist geschlossen. Die Suturen sind ron gewölnlieher Beschaffenheit. Die finochen sind hart. Der Hirnsolüidel ist nach allen Richtungen gut und in der Hauptsache symmetrisch ausgebildet und roldständig geschlossen. Die Innenfläche der Schädelkapsel ist ron der harten Hirnhaut in der gewöhnlichen Weise ausgekleidet. Die Falx ccrebsi fehll vollkommen. Das Tenterium ccrebelli inserirt oben rechts an der Diagonale des Seitenwandbeins, die rom vorderen inneren Winkel nach dem hinteren änsseren Winkel dieses linochens gezogen ist, links obel inserirt en etwas hinter dieser Diagonale. Es reicht in der Sagittallinie bis zur grossen Fontanelle heran. Von den genannten Insertionsstellen ziehen die Gewebsplatten des Tentorum cerebelli zur Schádelbasis. Sie heften sich also oben und ibbrigens aueh unten an der Scbädelbaisis weiter vorn an, als es sonst beim hinderschädel geschielt. Das Zelldach steht rechts noch weiter nach vorn, oben undaussen, als links und ist links dünner als rechts. Die die seitliche und die nutere Wand der linken Schläfengrube begrenzenden Knochen sind 
linlis etwas nach aussen vorgebuchtet. Der Raum zwischen Zeltdach, Stirnbein, rorderem Seitenwandbein, Schläfenbein und Felsenbein ist linkerseits grösser als rechterseits. Eine Grössenverschiedenheit zwischen der rechten und linken Hälfte des Schädeldachs findet sich nicht. Das Foramen Pacchioni d. i. das Toch, durch das der Hirnstamm unter dem Tentorium cerebelli nach vorn tritt, ist grösser als normal. Durch ein in das Hinterhauptbein gesägtes F'enster erkennt man, dass der Raum zwischen der rechten Hälfte der Hinterhauptschuppe und der rechten Hälfte des Zeltdachs, der ron der rechten Kleinhirnhemisphäre ausgefüllt ist, umfangreicher ist als der entsprechende Raum links. Die Erhebung, die das Felsenbein über die normale Scbädelbasis zeigt, fehlt links vollstandig.

Innerhalb der Schädelhohle fand sich in erster Linie klare Flüssigkeit. Luf der die Schädelbasis auskleidenden Dura lagerte nur eine an ihrer unteren Fläche etwa $1 \mathrm{~mm}$ dicke, namentlich rorn und unten stark vaskularisirte Membran, die in der Dicke von $1 / 2 \mathrm{~mm}$ auch innerhalb der. Dura der seitlichen, rorderen und oberen Schädelpartien vorhanden war. Diese Membran stellt einen an den Seiten und der unteren Fläche des aus dem Foramen Pacchioni in die Schädelhöhle hineinragenden Hirnrestes entspringenden, nach vorn gerichteten, im Längsdurchmesser $5 \mathrm{~cm}$ messenden Sack dar, der mit Cerebrospinalflïssigkeit gefüllt ist. An der Basis und vorn war ein Zwischenraum zwischen diesem Sack und der Dura nicht nachweisbar, wohl aber war ein mit Cerebrospinalnüssiglieit erfüllter Raum zwischen Dura und Sack an den Seiten und oben vorhanden. Dieser Sack stellt die embryonale unpaare Grosshirnblase dar; die Aussenseite entspricht der Pia, die Innenseite der Hirnrinde.

Abgesehen ron einer an der Convexität in der Sagittallinie dahinziehenden seichten Furche, besteht an der Grosshirnblase nirgends die Tendenz in zwei Halblcugeln zu zerfallen. Am oberen hinteren Theil der Blase befindet sich ein herzformiger, 5 Pfennigstück grosser Spalt vor der Oberfläche des unter dom Tentorium cerebelli herausragenden Hirnrestes. Durch diesen Spalt commnnicirt die im Innern der Grosshimblase befindliche Flüssiglieit mit der innerlalb des Stirnbeins, Schläfenbeins bezw. dem vorderen Theil des Seitenwandboins befindlichen Subduralflussigkeit. Die an die Seiten dieses herzförmigen Spaltes angrenzenden Randpartien sind die einzigen Stellen, an denen sich makroskopisch sichtbare, minimale Partien ron Grosshirnsubstanz vorfinden, links deutlicher als rochts, aber auch links nur in der Breite und Dicke von $1 / 2 \mathrm{~cm}$ und in der Länge von $2 \mathrm{~cm}$. Diese etwa zur oberen Occipitalwindung gehörige, einigermaassen entwickelte Grosshirnsubstanz ist, wie ein Durelnitt lehrt, auch nicht solides, sondern zerliüftetes Hirngewebe. Im Innern der Grosshirnblase tlottiren in der Nähe des rechten und linken Randes des herzformigen Spaltes due Plexus chorioidei.

Die Grosshirnblase wurde mitsammt dem Hirnstamm, dem Kleinhirn und dein Rückenmark im Zusammenhang aus der Leishe herausgenommen und zunächst makrosliopisch untersucht. Es ergal sich Folgendes:

Das Rückenmark misst vom unteren Salralmark bis zur Spitze der Schreib- 
feder $15 \frac{1}{2}$ cm. Es lässt im Lendennark wie im Halsmark ein Anschwellung erkennen. Sohon bei der äusseren Betrachtung bemerkt man deutiich, dass die Pyramidenanschwellung beiderseits vollständig fehlt. Die li n ke O live ist wesentlich grösser als die rechte. Die linke Olive springt an der ventralen.Seite der Medulla obl. - ähnlich wie das Corpus opticnm der Vögel - halbkugelförmıg hervor. Der Wurm des Kleinhirns steht nicht in der Mitte, sondern weiter nach links. Die rechte Hemisphäre des Kleinhirns ist wesentlich grösser als die linke. Nach Abtragung der Kleinhirnhemisphären sieht man deutlich, dass die von der rechten Kleinhirnhemisphäre ausgehenden Verbindungsarme (Bindearm zu don Vierhügeln, Brückenarm und Bindearn zum Strichīörper) voluminöser sind, als die gleichnamigen Gebilde ller linken Seite. An der: Basis des Hinterhirns liegen beide Nervi abducentes und beide Trigemini. Der oben bereits erwalnte, die unpaare Grosshimblase larstellende Sack entspringt an der oberen und beiderseits einen schmalen Spalt lassend, an den seitlichen Flächen des Mittelhirns bezw. direct vor der Bcücke. Seine untere Fläche ist, wie bereits erwähnt, dicker als seine seitlichen, oberen und vorderen Flächen. An dieser unteren Flïche befindet sich in der Sagittallinie eine Einsenkung, an deren hinterem Finde beinte Nervi oculomotorii liegen, und an deren vorderem Ende ein sebr dinnes Chiasma opticnm nicht zu verkennon ıst. Fin freilich unentwickelter Bulbus olfactorius ist wenigstens links vorhanden. Die obere Fläche des Sacks zeigt eine schmale, seichte Einsenkung. Des 5 pfennigstückgrossen Spaltes, den die Grosshirnblase hinten oben zeigt, ist bereits gedacht; ebenso des Befondes von einigermassen entwickelter Hirnsubstanz an seinen Rändern und der Plexus chorioidei einwärts dieser' Ränder. Zwischen dem herzformigen Spalt und dem Mittelhimdach liegt ein am Mittelhirn angewachsenes, dem Kehlliopfdeckel ähnliches Gebilde. Unter dieser Gewebsplatte befindet sich die Wündung ues Aquaeductus Sylvii. Ventral von diesem bemerkt man an der vorderen Wand des s. Z. ans dem Foramen Pacchioni herrortretenden IJimrestes d. i. der hinteren Wand unseres Sackes: zwei Höcker, einen grösseren rechten und einen kleineren linken, das verkümmerte Zwischenhirn darstellend. Eme unansehnliche Hypophyse lagert im Türkensattel. Von der Zirbeldrüse, war makroskopisch nichts aufzufinden. Die Gehirnblase war - abgesehen von dem Plexus — nur mit Flüssigkeit gefült. Es fehlen also die gesammte Grosshirnmarlisubstanz, der Balken, die yordere Commissur, der Fornix und die Oorpora mammillaria.

Zum Zwecke der mikroskopisohen Untersuchung wurde das gesammte Centralnervensystem, das sich in Formalin vorzüglich gehalten hatte, in einer concentrirten Lüsung von Kíali bichromicum gehärtet, mit slkohol entwässert, in Celloidm eingebettet und in 50 Mikron dicke Schnitle zerlegt.

Die Rückenmarlisschnitte wurden theils nach her Wejgert-WoJters'schen Methode theils mit Alaun-líarminlösung gefärbt. Besprechen wir zunächst die Kesultate der Markfaserfarbung, die mit Ze is $U$ cular 4 apochromatisches Objectiv 16,0 bezw. $8,0 \mathrm{~mm}$ fesigestellt wurden: 
Im Sakralmark (Fig. 1) fehlen markhaltige Nervenfasern an den dorsalsten Gebieten des rechten und linken Seitenstrangs; an der einen Seite ist die Randzone des dorsalen Seitenstrangs in Folge ron Einsenkung der Peri* pherie concar statt convex. Ein Theil der neben dem Sakralmark verlaufenden, quergetroffenen Nervenfaserbündel entbehrt in den, dem Rückenmark am nächsten gelegenen Partien des Marks. In den Vorderhörnern und in den Hinterhörnern ziehen markhaltige Fasern. Auch im unteren Lendenmark vermisst man Markfasern in den dorsalsten Partien der Seitenstränge. Die dorsalen Theile der Hinterhörner sind sehr umfangreich. Die Lissauer'sche Randzone enthält eine Anzabl feiner Fasern. Die vorderen und hinteren Wurzeln sind markhaltig. Die noben dem unteren Lendenmark verlaufenden, quergetroffenen Nervenbündel haben $z$. Th. kein Mark.

Im mittleren Lendenmark (Fig. 2) sind die dorsalsten Partien der Seitenstränge sehr schmal und arm an markhaltigen Fasern, namentlich in ihrem lateralen $\Lambda$ bschnitte. Die vorderen Wurzeln sind von den Vorderhörnem aus mit schönen, markhaltigen Fasern verseben; nirgends erbickt man von den Seitensträngen zu den Vorderhörnern ziehende Fasern; Commissurenfasern sind dentlich; die marlihaltigen hinteren Wurzeln strahlen durch die Hintersiränge in die graue Substanz der Hinterhörner ein und reichen z. Th. bis an die Basis der Hinterhörner heran.

Im oberen Lendenmark (Fig. 3) ist das rechte und linke dorsale Drittel der Seiteristränge ventral vom Kopf der Hinterhörner tief eingesun ken. Die dorsale Hälfte beider Seitenstränge ist in den der Peripherie anliegenden Theilen markfaserarm, auf der einen Seite mehr als auf der andern. Im unteren Brustmar'k befindet sich im dorsalen Theile des Seitenstrangs beiderseits eine zackenförmige, scharfe Einsenkung der Randzone. Die an die Einsenkung angrenzende Partie dés Seitenstrangs jst rechts wie links markfaserarm, ebenso der mediale Abschnitt des dorsalsten Viertels des Seitenstrangs. In beiden Hinterstrangen ist an der medialen Seite der Wurzelzone des Burdach'schen Stranges, ein heller Streifen zu bemerken. Auf einer Anzahl von Präparaten ist das Fasciculus sulcomarginalis des Vorderstranges fast faserlos.

Im mittleren Brustmark (Fig. 4) macht sich die von der Peripherio ausgehende Einsenkung an dem dorsalen $A$ bschnitt beider Seitenstränge sehr deutlich bemerkhar. Der mediale Theil des dorsălen Drittels der Seitenstränge ist faserarm. Im medialen Theile der Wurzelzone ist ein heller Fleck zu bemerken. Im oberen Brustmark (Fig. 5) ist die erwähnte Einsenkung sehr stark. Die ebenfalls erwähnte Faserarmuth in der Wurzelzone der Hinterstränge bezw. im Fasciculus sulcomarginalis ist auf manchen Präparaten mehr, auf anderen weniger dentlich. Im mitlleren Halsmark (Fig. 6) liegt ventral von der Lissauer'schen Randzone beiderseils eine faserarme Partie, die nur an der Peripherie reichlichere Markfasern enthält; weitẹr rentralwärts folgt die Einstülpung, die ron der Peripherie aus den dorsalen Seitenstrang beiderseits bis zur Hälfte seiner Breile spaltet. Der noch weiter ventralwarts folgende Seitenstrang ist bis zu einer, durch den Centralkanal gedachten Quer. 
linie, in der Mitte zwischen Randpartie und medaler Partie, faserarm - auf der einen Seite ist dies nur mikroskopisch dentlich. Ebenfalls nur mikroskiopisch scharf zu sehen ist die Faserarmuth des dorsalen Fünftels der medialen Goll'schen Stränge. Im oberen Halsmark finden sich die Einstülpung'en der Seitenstrangsperipherie wiederum. Die medialen Theile der dorsalen Hälfte der Seitenstränge sind faserarm. Die Gowers'sche Bündel sind an der Peripherie heller als die Kleinhirnseitenstränge. Das dorsale Drittel der mittleren Goll'schen Stränge ist faserarm. Noch ein Stück höher im Halsmark (Fig. T) ist eine periphere Einsenkung der dorsalen Seitenstränge nur noch andeutungsweise auf der linken Seite zu bemerken. Im Seitenstrang selbst ist der mittlere Theil der dorsalen und der periphere der rentralen Hältte faserarm. Das dorsalste Drittel des mittleren Abschnittes der Gollschen Stränge ist beiderseits sehr faserarm. An der Grenze des Goll'schen und Burdach'schen Stranges findet sich rechts und links ein hellerer Streifen, der namentlich die innere Partie des Burdach'schen Stranges trifft und ventral an die graue Substanz, dorsal jedoch nirgends an die Peripherie heranreicht - es dürfte sich um das Schultze'sche Komma handeln; ich bin nicht ganz sicher, ob die Hellerfärbung nicht z. Th. durch Auftreten des Kernes des Goll'scben Stranges bedingt ist. Auf rielen Präparaten erblickt man den Vervus accessorius. Vor der grauen Commissur ist eine mässig starke Faserkreuzung zu bemerken. Die Incisura longitudinalis anterior ist auffallend breit, vermutblich wegen des Ausfalls der Pyramidenvorderstränge, nur ganz vereinzelte Fasern ziehen aus der vorderen weissen Commissur an die der Incisur angrenzende Peripherie der Vorderstränge. Eine Pyramidenlireuzung ist nirgends zu bemerken.

Alle die besprochenen Segmente des Rückenmarks wurden auch mit Alaunkarmin- und Hämatoxylinkernfärbung behandelt. Es ergaben sich wenig Abnormitäten. Der Centralkanal ist in Sakralmarli kireisrund und offen, vom oberen Lendenmark nach oben ist er geschlossen. Seine Gestalit ist im unteren Lendenmark oval, jm mittleren Lendenmark ist sein dorsales Ende spitzwinklig, sein ventrales Ende rechtwinklig; seine Seiten stellen nach innen concave Bogenlinien dar. Im unteren Brustmark gleicht sein Querschnitt einem sphärischen Dreieck. Weiter nach oben nimmt er die verschiedenartigste Gestaltung an. Im oberen Lendenmark sind die Gefässe im Innern und an der Perjpherie stark gefüllt; in der vorderen Commissur befindet sich eine Blatung. Im unteren Brustmark ist die weiche Rückenmarkshaut besonders an der ventralen Seite verdickt und vor der Incisura longitndinalis anterior mit Rundzellen infiltrirt. Im oberen Brustmark ist eine starke Gefässfüllung vorhanden - besonders im dorsalen Theil der vorderen Incisur. Eine allgemeine mässige Verdickung der weichen Rückenmarkshäute bemerkt man im Halsmark.

Oberhalb des Halsmarks sind die Querschnitte nicht mehr symmetrisch, indem der dorsale Theil der linken Hälfte der Präparate um ein Beträchtliches umfangreicher ist. Dieser Massenzuwachs erstreckt sich zunächst auf das Hinterhorn. Das Centralnervensystem ist vom untersten Theil des Nachhirns bis hinauf zo dem rudinentären Zwischenhirn in eine fortlau- 
fend nummerirte lückenlose Schnittserie von der Dicke von 50 Mikren zerlegt. Die Schnitte wurden abwechselnd nach der Weigert-Wolters'schen Markscheidenmethode and mil Hämatoxylin- oder Alaunkarmin-Kernfärbung behaudelt. Es bewährte sich, del Wolters'schen Hämatoxylinlösung einige Tropfen einer 1 proc. wäsirigen Osmiumlösung zuzusetzen, um tief schwarze Fasern zu erhalten.

Betrachten wir zunächst die Schnitte, die mit der Weigert-WoltersFärbung behandelt worden sind, mit Hülfe des Mikroskops, so ist es mir an den ersten Präparaten der Serie zweifelhaft, in wieweit die in den Hintersträngen betindlichen helleren Stellen durch Faserarmuth, und in wieweil sie durch Auftreten der Kerne der Hinterstränge zu Stande gekommen sind. Sehr hell ist die gesammte mediale Partie des Goll'schen Stranges bis zur Peripherie; die Helligkeit der Randzone des Goll'schen Stranges ist jedenfalls durch Faserarmuth bedingt, denn der Kern reicht nicht bis hierher. Etwas hell ist der mediale Theil der Wurzelzone; in wieweit hier der äussere Kern der Keilstränge betheiligt ist, entzieht sich meiner Beurtheilung. Die linke dorsale Hälfte der Präparate ist wesentlich grösser als die rechte. Unmittelbar ventral for den Hinterhörnern zeigt das Nachhirn eine Einsenkung; dieselbo ist rechts mässig, links um Vieles bedeutender. Beiderseits ist der Seitenstrang im medialen Theil seiner dorsalen Hälfte sowie im peripheren Theil seines ventralen Abschnittes faserarm. Der Vorderstrang hat in der peripheren Randzone an der Umbiegungsstelle eine faserarme Stelle und zwar rechts und linls. Diese Verhältnisse sieht man z. B. in Präparat 21 sehr deutlich. In Präparat 24 erkennt man, dass die zur Kreuzung in der vorderen grauen Commissur heranziehenden Fasern von der Basis der Hinterhörner lrommen; es handelt sich also um Schleifenfasern und Schleifenkreuzung. Unsere Figar 8 ist die Photographie von Präparat 29; die Faserarmuth an der Umbiegungsstelle der Vorderstränge ist hier geringer als rorher. Die Schleifenkreuzung erstreckt sich auch in den höher gelegenen Präparaten nur auf eine mässige Anzahl von Fasern. Weiter nach aufwärts betrifft die Asymmetrie auch die ventralen Partien: links liegen die Fibrae arcuatae externae an der Seite an, ziehen um den Seitenstrang nach innen und ventralwärts. Im Präparat 46 sieht man linkerseits die Wurzel des Nervus vagus rechts noch nicht, beiderseits aber erkennt man die aufsteigende Glossopharyngeuswurzel. Der Centralcanal, der in Präp. 38 noch rentralwarts rom Mittelpunkt des dorsoventralen Durchmessers liegt, zeigt in Präp. 49 einen vielfach gezackten Querschnit, man kann 2 dorsale, 2 laterale und eine ventrale Zacke unterscheiden. In Präp. 51 findet sich der unterste Theil der linken unteren Olive; rechts liegt ventral rom Vorderstrang noch äusserst wenig Nervensubstanz. In Präp. 54 (Figur 9) ist die untere Olire links zu erkennen; ventral von ihr findet sich auch nicht einmal eine Andeutung ron der Pyramide: jedoch könnte vielleicht die medial ron ihr liegende Zone als Pyramidenstumpf aufzufassen sein, man betrachte die Photographie, auf der man auch an der rechlen rentralen Spitze des Schnittes etwas Aehnliches sieht. Der Vorderstrang ist auch links gut zu sehen. Ventral rom Vorderstrang und dorsomedial von der linken unteren 
Olive liegt beiderseits eme Nebenolive. Im Prap. 56 treten beiderseits die Wurzelfasern des Nervus hypoglossus auf. In Präp. 61 sind die dorsalen Theile des Goll'schen Stranges faserarm. Die Kleinhirnseitenstrangbahn ist rechts faserärmer. Median ron beiden Hypoglossuswurzeln liegen rechts und links die markfaserreichen Vorderstranggrundbündel und zwischen letzteren die Raphe. Die Vorderhörner, durch die die Hypoglossuswurzeln hindurchziehen, sind beiderseits deutlich vorhanden. In Präp. 66 ist der hintere Längseinschnitt immer breiter geworden, der Centralcanal ist immer weiter dorsalwärts getreten. Vom Vorderstranggrundbündel ist nur der dorsoventrale Schenkel noch vorhandan. Vom Vorderhorn erblickt man in Präp. 69 nur noch einen kleinen Rest. Die rordere Nebenolive ist beiderseits sehr dentlich, sie zerfällt in einen von zahlreichen Querfasern durehzogenen dorsoventralen und in einen liürzeren Querschenkel. Die hindurchziehenden Querfasern kommen ron den dorsolateralen Seiten des Präparats, ziehen zur Mittellinie und kreuzen sich daselbst. Die Vagus- und Glossopharyngeusfasern sind innerlialb des Schnittes und nach ihrem Austritt beiderseits deutlich. Im Präp. 73 ist Olive links voll ausgebildet, rechts ist sie dreimal so klein. Medial von der rechten Olive tritt die rechte Hypoglossuswurzel an den ventralen Rand Lejan. Aus dem Hilus beider Oliven sieht man Querfasern nach der Mittellinie ziehen und sich dort kreuzen. Die linke Olive ragt bei makroskopischer Betrachtung an der ventralen Seite etwa $2 \mathrm{~mm}$ mehr vor als die rechte. Ventralwärts von den Oliven liegen nur die Fibrae arcuatae externae. Von den Pyramiden fehlt alles. Figur 10 illustrirt diese Verhältnisse Im Präp. 81 ragt der dorsale Theil des Schnittes ca. $3 \mathrm{~mm}$ weiter nach links als nach rechts. In Präp. 89 ist der Centralcanal noch weiter dorsalwärts gerückt. Die rechte untere Olive ist noch grösser geworden; auch die linlie ist etwas gewachsen. Die Hypoglossuswurzeln sind in roller Schärfe zu sehen. In Präp. 94 geht ein Theil von ihnen in den Hilus der Oliven hinein. In Präp. 99 treten die Fasern des aufsteigenden Acusticus auf. Der Centralcanal wird immer zerklüfteter, erweitert sich aber erst im Präp. 127 zum vierten Ventrikel. In Präp. 116 sind die Wurzeln des Hypoglossus, des Vagus und Glossopharyngeus und des aufsteigenden Trigeminus rechts und links vorhanden, letztere schwach gefärbt. Die spinale Acusticuswurzel ist in Präp. 126 links dentlicher als reclits. Präp. 124 ist als Figur 11 wiedergegeben. In Präp. 129 ist die rechte Olive nach und nach grösser geworden, ist aber noch dentlich kleiner als die linke. Die linke Hypoglossuswurzel hat im Präp. 133 aufgehört; hjer jst đie linke Glossopharyngeuswurzel gut entwickelt. Die linke Olive beginnt mit Präp. 134 kleiner zu werden; offenbar handelt es sich hier bereits um ihre obersten Theile. Mit Präp. 139 ist auch die rechte Hypoglossuswurzel geschwunden, ebenso die linke Glossopharyngeuswurzel; die rechte ist noch da. Die laterale Acusticuswurzel zeigt sich in Präp. 141. In Präp. 144 beginnt sich der unterste Theil der Brücke an die ventrale Seite des Präparats zu lagern, und zwar zunächst als enn vollständig markfaserloses Querband. Schon seit Präparat 131 steht der dorsoventrale Laingsdurchmesser nicht in der Mittellinie, sondern schief und zwar in dem dorsalen Abschnitt 
mehr links, in dem ventralen mehr rechts. In Präp. 148 biegt die rechte aufsteigende Glossopharyngeusw urzel seitlich um und zieht nach aussen. Der aufsteigende Acusticuskern ist beiderseits deutlich zu sehen. In Präp. 159 bemerkt man links den Kernschenkel des Nervus facialis. Die linke Olive ist jetzt kleiner als die rechte; die letztere ist aber hier in ihrer vollsten Entwicklung getroffen, ist aber viel kleiner als die linke am Ort ihrer stärksten Entwicklung.

Die Brücke ist noch durch einen schmalen Spalt von der ventral von den Oliven gelegenen Schicht getrennl, sie zeigt ausser beiden Wurzeln des Abducens nur in ihrem dorsalen Theil und auch hier nur in der Mitte einige Fasern, im Uebrigen ist sie beinahe marlifaserlos. Links bemerkt man die laterale Acusticnswurzel, den accessorischen Acusticuskern sowie Trapezfasern. In Präp. 162 ist der Facialiskern links sehr deutlich, links ist ebenfalls bereits ein Stück Kleinhirn getroffen. In Präp. 165 ist die linke Olive sehr klein, auch die rechte hat wesentlich abgenommen, ist aber relativ noch grösser als die linke. Eia Spalt besteht zwischen Brücke und Präparat nur noch . rechts.

Rechts finden sich immer noch vereinzelte Glossopharyngeuswurzelfasern. Die laterale Acustieuswurzel ist auch rechts da. Im Präp. 170 ist die linke Olive garnicht mehr vorhanden, der Kernschenkel des Nervus facialis ist auch rechts zu bemerken, die T'rapezfasern sind beiderseits zu sehen. In Präp. 172 ist von der rechten unteren Olive nur noch eine Spur, in Präp. 174 nichts mehr wahrzunehmen. Die rechte und die linke mediale Acusticuswurzel sind deutlich zu sehen. Beiderseits bemerkt man den Abducenskern, links grösser als rechts. In Präp. 176 ist der dorsal von der Brücke gelegene Spalt abgesehen von der lateralsten Hälfte auch rechts geschlossen; die Brücke hat immer mehr an Grösse zugenommen. Abducensfasern finden sich links auch in den dorsalen Abschnitten. Auf derselben Seite ist der Austrittssehenkel der Facialiswurzel getroffen. Rechts bemerkt man die laterale und die mediale Acusticuswurzel. In Präp. 178 sind vorhanden: beiderseits Facialiskern, aufsteigende Facialisschenkel, Kernschenkel des Facialis, Abducenskern und - wurzel, aufsteigende und mediale Acnsticuswurzel, aufsteigende Trigeminuswurzel, Strickkörper, Schleife und Trapezfasern; nur links Austrittsschenkel der Facialiswurzel sowie Kleinhirn. Im dorsalsten Theil der Brücke finden sich einige Querfasern. Auch in Präp. 186 (Figur 12) bemerkt man den Austritts schenkel des Facialis nur links und zwar hier in starker Entwickelung. In dex Brücke, die noch mehr an Umfang zugenommen hat, sieht man nirgends Fasern, die zum Stratum superficiale oder zu den Pyramidenbündeln gehören. Nur mit stärkerer Vergrösserung vermag man ganz vereinzelte Fasern im Stratum complexum und einzelne mehr im Stratum profundum zu entdecken. In Präp. 190 sind obere Olive und centrale Haubenbahn rechts und links zu erblicken. Die hinteren Längsbündel sind hier stets vorhanden. Der erwähnte Spalt dorsal von der Brücke ist seit Präp. 186 vollständig geschlossen. Mit Präp. 198 ist die laterale Acusticuswurzel anch rechts in Wegfall gekommen, die mediale ist rechts sehr deutlich. Den Stricklörper sieht man auch rechts in das Kleinhirn einstrahlen; links war dies schon vor- 
her der Fall. In Präparat 213 begegnet man noch beiderseits einigen Abduceuswurzelfasern sowie der oberen Olive. Rechts sind der Fascialisanstrittsschenkel und die mediale $A$ custicuswurzel, links die cerebrale Trigeminuswurzel geiroffen. In Präp. 216 ist die Schleifengegend sehr reich an Querbündehn, die rom Kleinhirn und dem Strickkörper quer durch das Präparat ziehen und die Mittellinie vielfach überschreiten; die Schleife ist aber nicht sehr reich an Längsbundeln. In Präp. 221 liegen die austretenden Trigeminuswurzeln beiderseits an der lateralen Seite der Brücke. In Präp. 224 (Figur 13) treten im Stratum profundum pontis allmälig einige Fasern mehr anf. In Präp. 228 sind die der Mittellinie am nächsten liegenden Partien der Schleife arm an quergetroffenen, markhaltigen Fasern. Die cerebrale Trigeminuswurzel erscheint in Präp. 235 auch rechts. Der Brückenarm des Kleinhirns ist in Präp. 238 rechts deutlich breiter als links; nicht sehr reichliche Fasem strahlen yom Brückenarm in die dorsalen und medialen Seitentheile der Brücke ein. Die ventralen Seitenpartien der Brücke sind sehr faserarm. Die rentralen Mittelpartien der Brücke sind ohne alle Markfasem. In den zwei dorsalen Dritteln der Mittelpartie der Brüoke verlaufen von der Haube herziehend in der Mittellinie in dorsorentraler Richtung Fasern. Pyramidenbündel fehlen a uch hier gänzlich. In Präp. 248 ist beiderseits der untere Theil des Bindearms zu den Vierhigeln getroffen, ebenso die cerebrale Trigeminuswurzel und das hintere Längsbündel. Die Brückenarme, von denen der rechte voluminöser bleibt als der linke, sind im dorsomedialen Drittel faserarm, im ventro-lateralen Drittel nahezu faserlos. Im Präp. 249 beginnt beiderseits die laterale Schleife; die mittleren Partien der medialen Schleife bleiben arm an quergetroffenen, markhaltigen Nervenfasern. In Präp. 259 sind die Bindearme weiter ventralwarts getreten; der linke Bindearm ist weniger entwickelt als dex rechte. Von Präp. 260 an ist die dorsale linke Hälfte des Schnities stärker nach der dorsalen bezw. der lateralen Seite hin als die dorsale rechte Hälfte. Den Kern der lateralen Schleife sieht man in Präp. 261 rechts und links. In Präp. 263 tritt links der Kern der hinteren Vierhügel auf; die laterale Schleife ist links umfangreicher als rechts; in der Brücke finden sich an der ventralen Seite immer noch keine Fasem, in der Mitte wenig Fasern, nur in den dorsalen Abschnilten sind einzelue Faserzüge rorhanden. Pyramidenbündel fehlen auch hier rollständig. Noch immer ist der rechte Brückenarm wesentlich dicker als der linke, seine laterale Seite ist rechts und links faserärmer als die mediale. Der Nervus trigeminus ist an der medialen und der lateralen Seite der Brückenarme beiderseits schief getroffen. Die Ueberbrüokung des vierten Ventrikels begiunt auffallender Weise erst im Präp. 272. Rechte nnd linke laterale Schleife sind in Präp. 273 gleich gross. Der Bindearm bleibt rechts stärlier entwıckelt als links; die ventralen Bündel der Bindearme reichen bis an die Mittellinie heran. Vom Locus coeruleus sieht man in Präp. 276 weder links etwas noch rechts. Mit starker Vergrössexung kann man hier am ventralen Rand der Brücke wenigstens rechts einge sparliche Querfasern wahruehmen. In Präp. 278 beginnt die Bindearmkreuzung. Sie wird mit Präp. 289 eine vollständige. In Präp. 282 ist das dorsal vom 
Aquaeductus Sylvii gelegene Gebiet vollständig faserlos. Die cerebrale Trigeminuswurzel jst hier wie auf früheren Präparaten deullich. Dorsal von den lateralen Enden der hinteren Längsbündel bemerkt man beiderseits einen schmalon Zug quer verlaufender Nervenfasern, die als Wurzelfasern des Nerrus trochlearis aufzufassen sind. In Präp. 291 kommt der Kern der hinteren Vierhügel auch rechts zum Vorsehein. Die mediale Schleife ist immer mehr von der Mittellinie entfernt; jhre medialen Theile sind markfaserarm; das Bündel von der Schleife zum Fusse des Hirnschenkels ist nirgends zu entdecken. In Präp. 293 (Figur 14) ist der Trochleariskern in einer Einsenkung am dorsalen Rande des hinteren Längsbündels zu sehen; mit starker Vergrösserung erkennt man in dem dorsal vom Aquaeductus gelegenen Gebiet einige spärliche Querfasern. Der Grössenunterschied zwischen den hinteren Vierhügeln ist noch in Präp. 299 zu Ungunsten des linken deutlich. Der linke Brückenarm hört schon in Präp. 290 auf, nachdem er vorher immer schmäler geworden ist, der rechte Brückenarm erreicht sein Ënde erst in Präp. 301. Bis zu Präp. 319 bleibt die rechte Brückenhälfte etwas breiter und ragt lateralwärts weiter hervor. In Präp. 301 sieht man auf beiden Seiten den Kern der hinteren Vierhügel, die cerebrale Trigeminuswurzel, das hintere Längsbündel, die Bindearmkreuzung, die laterale Schleife, die verkleinerte mediale Schleife und die austretenden Trigeminuswurzeln. In der dorsalen Hälfte der Mittellinie der Brücke verlaufen einige Fasern in dorsoventraler Richtung. Im Stratum profundum und auch im complexum sieht man einige querverlaufende Fasern, rechts mahr als links, im ventralen Drittel der Brücke sieht man nur rechts einige wenige Fasern mit starkem Objectiv. Oculomotoriuswurzelfasern sind in Präparat 301 bei ihrem Durchtritt durch das hintere Längsbündel vorhanden, jn Präp. 205 reichen sie bis zur Bindearmkreuzung. Das Gebiet zwischen Brücke und Bindearmirreuzung ist markfaserlos. In Präp. 309 jst die laterale Schleife links nur noch andentungsweise, rechts stärker entwickelt zu bemerken. Die Brücke, in der Pyramidenbündel nach wie vor gänzlich fehlen, hat noch bis zu Präp. 330 eine beträchtliche Ausdehnung, dann wird sie kleiner. In Präp. 311 sind in dem dorsal rom Aquaeduct liegenden Gebiet zahlreichere Fasern. Am dorsalen Rand der Brüclie liegt von Präparat 312 ab ein Bündel quergetroffener Gefässe, das sich weiter nach aufwärts immer weiter seitlich ausdehnt, bis es in Präp. 329 die Pia an den Seiten erreicht. Dio Bindearmkreuzung ist mit Präp. 315 vollendet. Der linke weisse Kern der $\mathrm{Haube}$ ist hier deutlich stärker und markfaserreicher als der rechte. Die mediale Schleife ist dorsorentral gerichtet. Die rechto laterale Schleife ist noch vorhanden. In Präp. 331 ist der linke rothe Kern von mehr markhaltigen Fasern durchsetzt als der rechte und die Fasermasse, die medial vom linkon rothen Kern dorsoventral zieht, beträchtlicher als die medial vom rechten. Beiderseits liegen ventral vom rothen Kerne die Oculomotoriuswarzelfasern. In der Mittellinie des Haubenfeldes begegnet man sich kreuzenden Fasern. In der Brücke finden sich nur spärliche Fasern in den dorsalen Abschnitten. In Präp. 333 findet sich links am dorsalen Rand des Schnittes eine kleine Hervorbuchtung, in deren Innerem und an deren dorsalem 
Rande Nervenfaserzüge ziehen. Zwischen hinterem Vierhïgel und dieser klonen Hervorbuchtung bemerkt man an der linken lateralen Peripherie eine Einsenkung, die in Präp. 336 eine mit Gefüssen und Pia ausgefüllte Spalte wird. Die in Form einer Kuppe allmalig immer melir abgeschnürte Hervorbuchtung rückt allmälig mehr nach der Mitte, in Präp. $34 t$ liegt sie mehr zur rechten, in Präp. 350 ganz zur rechten Hälfte des Präparats, sie macht dann die dorsale Spitze der rechten Hälfte des Schnittes aus. Dieses Gebjlde scheint mir der atrophirte vordere Vierbügel zu sein; es ist in Präp. 337 (Figur 15) nicht deutlich zu erkennen. In diesem Präparat ist der dorsal von der Brücke auftretende Spalt deutlich. Die Brücke jst bereits kleiner geworden. Die Oculomotoriuswurzelfasern bemerkt man ventral von den rothen Kerneu, deren linker hier deutlich mehr markhaltige Fasern enthält und grösser ist als deren rechter. Die ausgetretenen Oculomotoriusfasern liegen seitlich von der Brücke; (auf böheren Schnitten erkennt man den Zusammenhang dieser letzteren mit den Oculomotoriuswurzeln). Yon der Substantia nigra Soemmeringii sieht man nichts. Die Hirnschenkelfüsse fehlen gänzlich. Lateralwärts von den rothen Kernen begegnet man einer Fasermasse, die der medialen Schleife entsprechen wird. Dorsal von den rothen Kernen befindet sich ein Faserfilz, in welchen Fasern aus dem sog. rentralen Abschnitte der hinteren Commissur einstrahlen. Die linteren Längsbündel sind in Präp. 349 zu sehen. Mit Präp. 351 tritt dorsal und lateral rom rothen Tern links ein neues, mächtiges Gebilde $A$ auf, in dem sich Ganglienzellengruppen und Nervenfasernetze finden, mit dessen Auftreten die mediale Schleife rerschwindet. Schon in Praparat 353 begegnen wir auch rechts einem neuem Crebilde B, das aber etwas ventraler und lateraler liegt als das rechtsseitige; ich glaube, dass es sich rechts und links um verschiedene Dinge handelt, links bei A wahrscheinlich um einen Thalamuskern. In Präp. 357 umsäumt links ein Faserzug a den lateralen Rand des Präparats. Vom dorsalen Rand des linken rothen Kerns zieht ein Faserzng $b$ in ventro-dorsaler Richtung dorsalwärts. A liegt dorsolateral rom linken rothen Kern, zwischen a und b. Seit Präp. 350 hat die Brücke an ihrem rentralen Rande eine Einsenkung erlitten und ist immer kleiner geworden. Mit Präp. 358 geht diese Einsenkung tiefer und theilt die Brücke in 2 Theile, von denen der rechte mit Präp. 361, der linke nit Prïp. 364 verschwindet. In Präp. 361 begegnet man den ausgetretenen Oculomotoriusfasern an der ventralen Seite des Präparats; das Gebiet ventral von den rothen Kernen ist von Fasern durchzogen, von denen ein Theil concentrisch zur ventralen Uimgrenzung des rothen Kerns verläuft. Mit dem Mikroskop erkennt man am ventralen Rande in einer schmalen Schicht Fasern, die in dorsoventraler Schichtung parallel zu einander verlaufen; diese Fasern scheinen zum ventralen Hirnschenkelfuss zu gehoren. A und B sind mächtiger geworden, zerfallen in Gangliengruppen and sind durchsetzt mit zahlreichen Nervenfasernetzen. Der Faserzug a ist links mächtiger geworden, tritı ein wenig yom Rande nach innen and setzt sich in Präp. 365 ventralwärts fort in den als verkümmerten linken Hirnschenkelfuss aufgefassten Faserzug. In Präp. 367 weist der linke Faserzug a fünfmal pinselformige Ausstrahlungen nach der 
Seite an seiner dorsalen Hälfte auf. In Präp. 369 sind die rothen Kerne beiderseits sehr klein geworden, der linke ist immer noch reicher an Fasern als der rechte. Der sog. ventrale Abschnitt der hinteren Commissur ist noch zu sehen. A ist stark ausgebildet und hat an seiner ventralen Seile einen besonders dichten Filz von Fasern, aus dem sich Zuige zur ventralen Hälfte von a begeben. Das dorsolateral vom rechten rothen Kern gelegene Gebilde B ist durch drei ron innen nach aussen ziehende Fasernetze in Glieder abgetheilt und zeigt dadurch eine völlig andere Structur als A. Mit Präp. 373 hören die rothen Kerne beiderseits gänzlich auf. Der lotzte Rest von der hinteren Commissur ist in Präp. 385 zu sehen. Links und rechts ist der Faserzug a deutlieh. Das Präparat ist an der ventralen Seite wesentlich kleiner geworden. Der Einschnitt an der dorsalen Seite des Präparats entspricht dem vordersten Theil des Aquaeductus Sylvii, über dem der sog. dorsale Abschnitt der hinteren Commissur fehlt. Weiter nach aufwärts werden A und B immer kleiner, zuerst A. In Praparat 415 ist rechts Faserzug a deutlich. Die linke Hälfte des Präparates wird weiterhin immer kleiner, in Präparal 495 ist sie vollständig faserlos; die rechte Hälfte enthält noch Fasern und zwar liegt etwas einwärts vom lateralen Rande Faserzug a, an dem man 4-5 pinselförmige Ausstrahlungen nach dem rechten Rande zu bemerkt. Die Abtheilung in Glieder ist noch in Präparat 439 zu sehen; der Schnitt durch den rechten Theil des Präparats ist durch zwei Nervenfaserzüge in mehrere Abschnilte getheilt; am dorsalen Theil des lateralen Randes liegt Faserzug a, am rentralen Rand befindet sich ein schmaler Faserstreifen. In Präp. 451 ist der linke Höcker, ron dem bei der makroskopischen Beschreibung die Rede war, nicht mehr getroffen, der Schnitt umfasst uur noch den rechten Hörker, der immer kleiner wird. Der rechte Höcler zeigt in Präp. 463 nur noch einen einzigen Faserzug, der, von der Mitte des markfaserhaltigen ventromedialen Randes ausgehend, das Präparat in eine grössere innere und in eine kleinere äussere Partie zerlegt. In Präp. 478 hat dieser innere Faserzug ganz aufgehört; dies Präparat hat nur noch die Grösse einer Linse, die einwärts von ihrer Peripherie an drei viertel Theilen ihres Umfanges einen feinen Marlifaserzug erkennen lässt.

Wenn man Nachhirn, Hinterhirn, Mittelhirn und das unentwickelt gebliekene Zwischenhirn an den Präparaten, die theils mit Hämatoxylin, theils Alauncarmin gefärbt sind, betracitet, so bemerkt man folgende Besonderbeiten: In Präparat 7 sind die Gliakerne in der Umgebung des Centralcanals vermehrt, ebenso auf vielen folgenden Präparaten. In Präp. 17 und Umgebung findet sich namentlich an den Seitentheilen eine Verdickung und kleinzellige Infiltration der weichen Rückenmarkshäute; dieselbe ist links in der tieferen Einsenkung, die die Peripherie ventral von den Hinterhörnern erfahren hat, ziemlich stark. Die Gefässe sind besonders an der ventralen Seite stark gefüllt; an einzelnen Stellen z. B. in Präp. 32 liegt innerhalb der weichen Häute ausserhalb von Gefässen Blutfarbstoff. Der Centralcanal zejgt an verschiedenen Präparaten verschiedenartige Querschnittsbilder; bald ist er oval, bald zeigt er mehrere Ein- und Ausbuchtungen z. B. in Präp. 45. In Präp. 47 ist das 
ausserhalb von Gefässen liegende Blut an der vorderen Langsfissur besonders reichlich und zeigt zahlreiche Kilumpehen von Hänatoidin. In Präp. 50 sind die seitlichen Ausbuchtungen des Centralcanals bedeutend. In Präp. 57 besteht der Centralcanal aus zwei, durch eine Brücke von Nervensubstanz getrennten Tlheilen. In Präp. 62 betrifft die Verdickung der weichen Rückenmarkshäute namentlich die lateralen und die dorsalen Theile. In Präp. 67 befindet sich ein kleinerer Rundzellenherd neben eincm Gefäss, welcher in Präparat 70 ein structurloses Centrum aufweist.

Weiter nach oben finden sich kleine Rundzellenleerde noch hier und da; ihr Centrum enthält aber immer Kerne. In Präp. 67 ist der Centralcanal wieder einheitlich, in Präp. 75 ist er ausgesprochen länglich und liegt hier an der Grenze des dorsalen und des mittleren Drittels der Mittellinie. In Präp. 80 stellt der Centralcanal einen längeren, länglichen Spalt dar, dem weiter dorsalwärts ein kleinerer ovaler Querschnitt beigefügt ist. Letzterer zerfällt in Präp. 85 gabelförmig in zwei Aeste. In Präp. 87 ist der Centralcanal wieder einheillich und besteht aus einem länglichen Spalt, dessen Länge ein Viertel des dorsoventralen Durchmessers des Schnittes beträgt. Die dorsolateralen Aussenwinliel des Schnittes zeigen reichliches Plexusgewebe. In Präp. 92 ljegen zwischen den am Boden des 4. Ventrikels liegenden Gefässen an zwei Stellen kleine Haufen von Rundzellen; im Innern des Centralcanals liegen Endothelzellenhaufen mit reichlichem, gelbbraunem, bei Carminfärbung sichtbarem Pigment. Der Centralcanal ist in Präp. 97 stark zerklüftet ond zerfällt in einen rechten und in einen linken Ast, die in einem spitzen Winkel aneinander liegen. Am Ende des linkev Centralcanales liegt mitten im Lumen Pigment. In Präp. 107 reichen die Nebenäste des Centralcanals bis an den Boden des 4. Ventrikels heran; letzterer zeigt in Präp. 115 namentlich links lebhafte Wucherung von Endothelzellen. In Präp. 127 ist der Centraleanal in die unterste Partie des Calamus scriptorius übergegangen; rechts und links fallen am Boden des 4. Ventrikels mit Endothelzellen besetzte Einbuchtungen oder durch Wucherung dieser Zellen bedingte Erhebungen auf. In Präp. 140 ist der Boden des 4. Ventrikels glatt und hat nur in der Mitte eine scharfe Einsenkung. Nirgends sieht man hier eine Abnormität an den Gefássen; die weichen Iirnhäute sind weder verdickt noch mit Rundzellen infiltrirt. Anch in Präp. 161 weist die Oberfläche des 4. Ventrikels kleine Erhebungen anf, die durch Wucherung des Endothels zu Stande gekommen sind. In Präp. 167 finden sich links mebrfache tiefe Einsenkungen am Boden des 4. Ventrikels und an den Wandungen dieser Einsenkungen liegen zahlreiche Endothelzellen. In Prap. 184 bemerkt man zwei besonders tiefe Einzuchtungen mit zahlreichen Verästelungen in der rechten bezw. der linken Seitenpartie des Bodens des 4. Ventrikels; in der Umgebung dioser in der Gegend des aufsteigenden Acusticuskerns befindlichen Höhlnngen ist die Glia reichlich gewuchert. Auch in Präp. 191 ff. sind die seitlichen Einbuchtungen sebr stark. Die in der Mitte des Bodens des 4. Ventrikels befindliche dorsale Incisur ist in Präp. 197 sehr tief und zeigt seitliche Verästelungen, sowie Wucherung yon Endothelzellen. In Präp. 206 findet sich, rentral ton dem in der Mittellinie liegenden Längs- 
einschnitt des 4. Ventrikels, noch ein abgeschnürtes, quergetroffenes, mit, Endothel besetztes Stück Centrallianal, das die Gestalt einer Ellipse hat. In Präp. 212 und 217 sieht man 2 derartige Ellipsen neben einander, in Präp. 222 ist wieder nur eine rorhanden. Mıl Pläp. 275, in dem der 4. Ventrikel überdacht, also zum Aquaeductus Sylvii geschlossen ist, zieht als ventraler Theil des Aquaeductus in der Mittellinie eine schmale tiefe Längsfurche. Nach links zeigt der Aquaeduct eine lange, nach rechts eine linze, dorsolateral gehende, schmale Einbuchtung. In Präp. 277 geht um das linke und um das rechte seitliche Ende des Aquaeducts reichliche Wucherung ron Gliazellen herum. In Präp. $280 \mathrm{ff}$. sind die an der ventralen Seite des Präparates gelegenen Blutgefässe stark gefüllt. Der Aquaeduct ist in Präp. 282 einem Fünfeck vergleichbar, indem neben der ventralen Einbuchtung in der Mittellinie noch beiderseits je 2 Einbuchtungen bestehen; die eine der letzteren zieht ventrolateral, die andere dorsolateral; die Tiefe der Einbuchtungen ist rechts and links nicht verschieden. In Präp. 292 ist die Gestaltung des Aquaeducts eine ganz nnregelnässige geworden, die Pia zeigt an den Seiten in der Nähe der Randzone zahlreiche alte Hämatoidinkömehen. In Präp. 300 bemerkt man neben dem Aquaeduct reichliches, z. Th. in Schläuchen angeordnetes Endothelgewebe, dic Pia enthält auch hier reichliche, bräunliche Körnchen. - In vielen grösseren Gefässen sieht man bei Carmin- wie bei Hämatoxylinfärbung inmitten der rothen Blutkörperchen mehr weniger rundliche oder längliche, schwärzliche Körnchen, z. B. in Präp. 314. Die Gefässe sind namentlich an der Peripherie und zwar sowohl der rentralen als der dorsalen stark gefült. In Präp. 318 sind die Wandungen des Aquaeducts mit Endothelzellen besetzt, sodass nur ein schmaler Längsspalt offen bleibt; um den Aquaeductus herum liegt selar reichliches Endothelgewehe. An den Aussenseiten der Schnitte finden sich hier und zwischen Haube, Brücke und Kleinhirn kleine Häufchen von Rundzellen, sowie von Pigment. In Präp. $326 \mathrm{ff}$. zeigen einzelne, in dem queren Spalt zwischen Brücke und Haube liegende mittelgrosse Gefässe schwarze Streifen und schwarze Punkte. Die Streifen sind an einzelnen Gefässen unter einander parallel. Streifen und Punkte sitzen ausschliesslich an der inneren Wand; ausserdem finden sich im Innern der Gefässe zwjschen den Blutkörperchen die bereits elwähnten schwarzen grösseren und kieineren Klumpen. In Präp. 344 bemerlit man die schwarzen Streifen an der Gefässwand auch an dex linken Aussenseite des Präparats. Die erwahnte Gefässwandveränderung, die Herr Dr. Schmor l für ein durch Formalin bewirktes Kunstproduct hält, ist nus an Präparaten deutlich, die mit Hämatoxylinkernfärbung oder mit Cochenillealaun- bezw. Boraxcarminfärbung behandelt worden sind, sie sind nicht sichtbar an Schnitten, die auf Markfaserverhällnisse gefärbt wurden. In Präp. 330 liegt dorsal vom Aquaeductus eine reichliche Menge Endothelzellen-haltigen Gewebes, in Form eines Dreiecks angeordnet. In Präp. 332 folgt dorsalwärts von diesem Gewebe ein Gebiet, in dem zahlreiche braungelbe Pigmentkörnchen liegen. In dieser ganzen Gegend sind die Gefässe, namentlich an der Peripherie, stark gefüllt, z. B. auch in Präp. 338. Hier ist der Aquaeduct sehr schmal. In Präp. 356 ist das Gewebe, 
das sich in dem Spalt zwischen der immer kleiner werdenden Brücke und der Haube befindet, reichlich mit Rnndzellen durchsetzt. In Präp. 360ff. geht vom Aquaeduct, der durch Epithelwacherung sehr eng ist, nach der ventralen Seite der Ifaube eine Endothelzellenleiste hin. In Präp. 374 vergrössert sich der Aquaeduct, in Präp. 378 noch mehr, zu einem dorsoventralen, länglichen, schmalen Raum. Mit 380 ist der Aquaeduct nicht mehr überdacht, ventralwärts hat er einen sehr tiefen Einsehnitt. Dio dorsale Partie des rechts rom dritten Ventrikel gelegenen Theils des Präparates ist in $398 \mathrm{ff}$. zerklüftet, sehr gefässreich. Die Gefässe sind blutreich. Ausserbalb der Gefässe liegen Blutzellen und Blutfarbstoff. In Präp. 401 zieht die Endothellage des vordersten Theils des Aquaeducts auf die rechte und die linke dorsale Endfläche. Innerhalb des Präparats ziebt eine Zellenlage von dem ventralen Ende des Aquaeducts und parallel zum dorsalen Rand und zwar rechts innen ron der gesammten do1salen Partie. Mit Präp. 414 hört der tiefe Einschnitt nach der ventralen Richtung auf. Zwischen dem grössten rechten und dem kleineren linken Theil des Schnitles liegen zahlreiche Pigmentkörnchen. Von Präp. 416 ab ist am linken dorsolateralen Aussenwinkel des Schnittes der Plexus zu sehen. In der Umgebung der stark gefüllten Piagefässe finden sich einzelne Kundzellenhäufchen. In Präp. 132 enthalten die dorsalen Theile des Schnittes reichliche braune Pigmentliörmchen. Der linke Plexus ist gewachsen. Die Gefässe sind stark gefüllt. An verschiedenen Stellen finden sich hier und an anderen Präparaten beträchtliche Gliawucherungen. Ganglienzellengruppen, die zwischen die Faserzüge eingestreut sind, verleiben dem Präparate dieser Gegend eine veränderte Zeichnung. In Präp. 440 bemerkt man am lateralen Rande des rechten Höckers, von dem bei der malsroskopischen Beschreibung die Rede war, quergetroffene Endothelschläuche. Mit Präp. 446 ist der rechte Plexus dentlich zu sehen. Im rechten dorsalen Absehnitt finden sich mehrfach Cysten. In Präp. 452 sind Ganglienzellenhauten grösseren Umfangs, dıe aus grossen Zellen bestehen, zu bemerken; in Präp. 470 und 474 nehmen diese Haufen das Centrum des allein noch aus dem rechten Höcher bestehenden Schnittes ein. Der linke Höcker ist schon in Präp. 446 vom rechten total abgetrennt und hört mit Präp. 450 ganz auf. In Präp. 462 zeigt der rechte Höclier auf dem Schnitt einige Cysten. In Präp. 476 findet sich am Rande des Präparats ein dichter Saum ron Zellen.

Das Kleinhirn wurde nach der Härtung durch einen Sagittalschnitt in der Mitte des Wurms getheilt; seine Verbindungen mit Bindearm, Brüekenarm und Strickkörper wurden beiderseits gelöst. Nach Durchtränkung mit Celloidin erfolgte Aufbeltung auf der durch den Wurm gelegten Schnittläche und Zertheilung in Sagittalschnitte von je $50 \mathrm{~mm}$ Dicke, die mit der WeigertWolters'schen Markscheidenfärbung behandelt wurden. Ein Theil der Schnitte wurde darnach mit Alauncarminlosung nachgefärbt, wodurch sich ausser den schwarzen markhaltigen Faserzügen noch die dunkelrothen zellenhaltigen Kleinhirnrindengebiete von dem marls- und zellenlosen blassrothen Untergrund deutlich abheben. Die Schnilte jeder Kleinhirnhälfte wurden vom Wurm aus nummerirt. Die Iinke Kleinhirnbemisphäre zerfiel in 220 , die 
rechte in 500 Schnitte. Die Schnitte sind an entsprechender Stelle rechts wesentlich höher and länger. Der umfangreichste Schnitt der rechten Kleinhirnhemisphäre, Präparat 240 , ist $32 \mathrm{~mm}$ lang und $22 \mathrm{~mm}$ hoch. Der umfangreichste Schnitt der linken Hemisphäre, Präp. 80, ist $26 \mathrm{~mm}$ lang und $18 \mathrm{~mm}$ hoch. Das rechte Corpus dentatum ist wesentlich grösser als das linke; es ist rechts ron Präparat 60 bis zu Schnitt 240 zu sehen, links findet es sich in den Präparaten 40 bis 140.

Eine Durchmusterung der linksseitigen Kleinhirnsagittalschnitle (Figur 16 stellt einen linksseitigen Kleinhirnschnitt in sagittaler Richtung dar) lehrt, dass in Präp. 40 der ventrale Abschnitt der vorderen Zweidrittel des Markkerns marlifaserlos ist, während die Läppehen gleichgut markfaserhaltig erscheinen. In Präp. 60 ist das mittlere Drittel vom vorderen Theil des Corpus dentatum an bis nach vorn markfaserlos. In Präp. 80 hat das Corpus dentatum seine grösste Ausdehnung. In Präp. 100 ist der vordere dorsale und ventrale Theil (also der ganze vordere Abschnitt des Markkerns von oben bis unten) und der vertrale mittlere Theil markfaserlos. In Präp. 120 ist der ganze vordere Theil des Markkerns markfaserlos und dorsal vom Corpus dentatum befindet sich im mittleren und hinteren Theil des Marlikernes ein heller, markfaserloser Streifen. In Präp. 140 ist der kleine Theil des Markkernes, der noch zu sehen ist, markfaserlos. Die hinteren Läppchen enthalten genügende Markfassern. Mit Präp. 160 ist der Markkern vollständig zu Ende. Auf den rechtsseitigen Kleinhirnsagittalschnitten (Figur 17 stellt einen solchen Schnitt dar) sind in Präp. 20 die vordersten Läppchen fast markfaserlos. In Präp. 60 enthalten die vordersten und die ventral vom Markkern gelegenen Iäppchen keine Markfasern. In Präp. 100 ist das ventrale Drittel des Markkernes ohne markhaltige Fasern; auch der ventrale Theil des Corpus dentatum ist unscharf. Die Läppchen enthalten in Präp. 120 gute Fasern, der ventrale Theil des Markkerns bleibt faserlos. In Präp. 140 ist die ventrale Hälfte des Markkerns ohne Markfasern. In Präp. 140 und 160 sind die ventralen und die hinteren Läppohen aufallend kleiner und weniger reich verästelt sowie arm an Markfasern. In Präp. 180 sind die ventralen und die hinteren Läppchen ebenfalls hypoplastisch. Das Corpus dentatum hat hier seine mächtigste Ausdehnung. In Präp.220 ist der Markkern, abgesehen von seiner dorsalen Partie, markfaserarm, aber nicht markfaserlos, die hinteren Läppchen haben ebenfalls nur spärliche Warkfasern. In Präp. 260 handelt es sich wiederum um Markfaserarmuth des Markkerns sowie um Hypoplasie der hinteren ventralen Läppchen. In Präp. 300 ist der ventrale Theil des Markkerns sehr faserarm, seine Mitte faserlos; die vorderen ventralen Läppchen enthalten genügende Markbündel, die hinteren ventralen Läppchen sind faserlos und hypoplastisch. Der Markkern ist in Präp. $320 \mathrm{zu}$ Ende. In Präp. 340 finden sich hinten und oben noch einzelne Faserbündel mit llark. Von Präp. 420 ab handelt es sich nur noch um Rindensubstanz. Nicht unerwähnt sei der bedeutende Blutreichthum der Gefässe in der gesammten Kleinhirnmarksubstanz.

Auf Schnitten durch die nur $1 / 2 \mathrm{~mm}$ dicke, kleine Partie von 
Grosshrnblasonwand erkennt man nach Farbung ron Lrankamin be starker Vergrösserung in Reih und Glied stehende kleine Ganglienzellen, auch solche mit dreieckigem Zelleib. In der etwas mehr entwickelten linken hinteren Occipitalwindung finden sich ausser Ganglienzellen auch einzelne markhaltige Nervenfasera, die den radiären Bindeln anzugehören scheinen, ferner Endothelschlänche - ähnlich denen in der Lmgebung des Centralcanals -, endlich lebhaft gewucherte Glia.

Die auffallendste Erscheinung unseres Falles dürfte der fast vollständige Iangel ausgebildeten Grosslirns bei entwickeltem Hirnschädel darstellen, bei einem Schädel, der in seinen Maassen und und in seiner Configuration sich von einem gleichalterigen Kinderscbädel mit normalem, ausgebildetem Grosshirn nicht allzusehr unterscheidet. In diesem Ausnahmefalle hat also eine Beziehung zwischen Schïdelwachsthum und Hirnwachsthum nicht bestanden. Nur der Druck im Schädelinnern kamn in Frage kommes, wenn der Schädel nicht ausschliesslich im Sinne der Gesetze der Vererbung geformt ist. B. von Gudden beschreibt in seiner Arbeit: "Leber das Gehirn und den Schätel eines neugeborenen Idioten" (Gesammelte und hinterlassene Abhandlungen, herausgegeben von Grashey. Wiesbaden 1889. S. 216.) einen Fall, bei dem die Grosshirnhemisphären stark verkümmert waren und in ihrem grössten Querdurchmesser nur $39 \mathrm{~mm}$ maassen; er fand den Schüdel trotzdem völlig normal und gesteht, dass ihm dieses Schädelwachsthum völlig räthselhaft sei.

Das Tentorium cerebelli inserirte in unserem Falle wesentlich zu weit vorn. Soll es, wie Hyrtl betont, die Halbkugeln des kleinen Gehirns vor Druck schützen, so wird es, wenn diese Last fehlt, weiter nach vorn liegen können, - wenn der Schädel ausgebildet ist. Auch die Falx cerebri haben wir vermisst. Soll die grosse Hirnsichel den nachtheiligen Druck beseitigen, den eine Grosshirnhemisphäre bei Seitenlage des Schädels auf die andere ausübt, so kann sie bei Fehlen der Hemisphäre des Grosshirns in Wegfall kommen. Dass die unentwickelte Grosshirnblase trotz ihrer Ausdehnung nahezu unpaar geblieben ist, steht mit dem Fehlen der Hirnsichel in Einklang. Nicht Wunder kann es nehmen, dass bei Mangel der gesammten Grosshirnmarksubstanz die vordere Commissur, der Balken, die Corporamammillaria, der Fornix und der sog. dorsale Abschnitt der hinteren Commissur fehlen.

Wenn das Grosshirn fehlt, so müssen auch alle die Fasersysteme in Wegfall kommen, die rom Grosshirn ihren Ursprung nehmen. Dies ist in unserem Falle durchans bewahrheitet. Der wichtigste Befund am Hirnstanm und Rückenmark, der durch die beigegebenen Figuren illustrirt werden dürfte, ist das rollständige Fehlen der Pyramidenbahn. 
Schon bei makroskopischer Betrachtung vermissten wir Hirnschenkel und Pyramiden. Mikroskopisch ergab sich, dass die weisse Substanz des Rückenmarks an allen den Stellen, wo die Pyramidenstränge liegen sollen, verschmälert - ja vielfach direkt eingesunken ist. Die betreffenden Rückenmarksschnitte zeigen überall da, wo die Pyramidenstränge liegen sollen, Agenesie. Die Pyramidenkreuzung fehlt vollständig. Da die Pyramiden total unentwickelt geblieben sind, sind im Nachbirn am ventralen Saum der Präparate die Oliven gelagert. Auf den Querschnitten der Brücke treffen wir auch nicht auf eins der bekannten quergetroffenen Pyramidenbündel.

Von Interesse ist, dass auch in unserem Falle das Schultze'sche Komma in den Hintersträngen des oberen Cervikalmarks olne Markfasern ist.

Mit lehhafter Spannung sah ich bei der Untersuchung dem Befund der Brïckenfaserung entgegen. Iu ibrer äusseren Configuration ist die Brïcke angelegt, innerlich ist sie aber ausserordentlich arm an markhaltigen Nervenfasern. Stratum superficiale und Stratum complexum entbebren der markhaltigen Nervenfasern vollkommen, nur im Stratum profundum fanden sich einige Züge ausgebildeter Markfasem. Das Corpus trapezoides ist markhaltig. Die von der Brücke ins Kleinhirn hinaufziehenden Brïckenarme enthalten nur eine kleine Zabl von Fasern. Namentich der ventrale Theil des Markkerns ist in beiden Kleinhirnhemisphären fast vollständig faserlos 1 ). Zu berücksichtigen wird sein, ob die in der Brücke fehlenden Fasern am 6. Tag normalerweise markhaltig sind. Herr Geheimrath Flechsig hatte die Güte mir an seinen Präparaten zll zeigen, dass dies der Fall ist ${ }^{2}$ ). Es mag dahingestellt bleiben, ob die an den ventralen und hinteren Läppchen der rechten Kleinhirinhemisphäre beschriebene Hypoplasie (siehe Figur 17) in Zusammenhang mit der Marklosigkeit der Brückenbahn steht.

Da der gesammte Stabkranz fehlt, sind auch die Thalami optici hochgradigst verkümmert.

Die mediale Schleife hat Defecte. Die Photographien zeigen, dass die unteren Oliven viel näher an der Raphe liegen, dass die Olivenzwischenschicht viel schmäler ist als an normalen Präparaten, dass die mittleren Partien der medialen Schleife mangelhaft ausgebildet sind.

1) Es wäre wichtig festzustellen, ob diese Faserzüge bei der Paralyse degenerirt sind; handelt es sich doch da um oft sehr bedentende Erlkrankung inrer Ursprungsstelle in der Hirnrinde.

2) An einem von mir untersuchten gleichaltrigen Fall (siehe unten!) waren die Brückenfasern sẹhr markarm. 
Ob diese Kleinheit der medialen Schleife allein ron dem llangel tes Grosshimrinde abhängt, ist im rorliegenden Falle wegen der küunmulichen Entwicklung der Thalami optici nicht zu entscheiden. Im oheren Halsmark ist die Schleifenkreuzung unverkennbar zu sehell, aber sehr klein. Die Markfaserlosigkeit der dorsalsten Partie der Goll'schen Stränge im oberen Halsmark bezw. im untersten Nachhirn ist bomerkenswerth. Die Hinterstränge besitzen im Debrigen ihr Mark beinahe vollständig. Die hinteren und ebenso die vorderen Rückenmarkswurzeln sind markhaltig. In der grauen Substanz vermisst man die Züge, die von den dorsalen Theilen der Seitenstränge normalerweise nach den Vorderhömern ziehen. Inwiefern die mangelhatte Ausbildung einzelner Abschnitte der Kleinhirnsejtensträngo bezw. dex Gowers'schen Bündel pathologisch sind, müssen normale Verglcichspräparate Jehren.

Von den Hirunerven sind der dritte bis zwölfte in grösster Schärfo zu sehen. Die hinteren Längsbündel sind vorbanden. Weder die cercbrale und die spinale Trigeminuswurzel noch die aufsteigende Acusticuswurzel, noch die spinale Glossopharyngeuswurzel fehlen.

Das Kind war mit 2 wohlgebildeten Augen ausgestattet. Beide Servi optici zeigen bei der mikroskopischen Untersuchung nach Färbung mit Hämatoxylin-Eosinlösung innerhalb ihrer Duralscheide die Arachnoidea und die Pia und im Lumen ausser der Arteria und Vena centralis ausserordentlich zahlreiche z. Th. mit Blut gefüllte Gefässe; auf dem rechten Opticusquerschnitt konnte ichetwa 60 Gefässlumina zählen, auf dem linken ist ihre Zahl noch grösser. Den linken Opticus habe ich auch mit der Weigert-Wolters'scben Markscheidenmethode behandelt; auch nicht eine markhaltige Nervenfaser ist zu entdecken gewesen. Die Gefässe im Opticus laufen den Centralgefässen parallel und kömen auf Horizontalschnitten durch das Auge, die den Sehnerv bei seinem Eintritt in den Bulbus treffen, bis zu den Lamina cribrosa verfolgt werden. Bekanntlich bat Ganser in seiner Arbeit: Ueber die periphere und centrale Anordnung der Sehnervenfasern u. s. w. (Archiv für Psychiatrie und Nervenkrankheiten. 13. Band. Seite $341 \mathrm{ffi}$.) dargethan, dass die Ganglienzellenschicht der Retina bei Atrophie des Nervus opticus fehlt. Lnser Fall bestätigt diesen Lehrsatz. Die betr. Präparate ]assen auch mit Nissl's llethylenblau nur äusserst spärliche Ganglienzellen erkennen. So stark verschmalert, wie von Ganser so elegant gezeichnet, ist die Nerventasel- und Ganglienzelleisschicht in unseren Präparaten jedoch nicht. Im Einklang mit der Markfaserlosigkeit der Nervi optici und 
mit dem Unentwickeltsein der Hirnrinde, würde die supponirte Hypoplasie der vorderen Vierhïgel stehen.

Eine wichtige Eigenthümlichkeit des beschriebenen Falles sind die hochgradigen Asymmetrien zwischen rechtsseitigen und linksseitigen Hirntheilen. In Folge verschiedener Grösse desselben Gebildes auf der rechten und linken Seite fanden sich diese Asymmetrien nicht nur im Querschnittsbild, auch in der Längsachse sind durch diese Grössenunterschiede wesentliche Verschiebungen zu Stande gekommen.

Schon makroskopisch war zu sehen, dass die rechte Kleinhirnhemisphäre wesentlich grösser ist als die linke. Der Wurm stand um ein beträchtliches Stück links von der Mittellinie. Der Bindearm zu den Vierhügeln, der aus der rechten grösseren Kleinhirnhemisphäre entspringt, ist voluminöser als der von der linken, kleineren ausgehende. Der rechtsseitige Brückenarm ist um vieles grösser als der linksseitige. Die der grösseren Kleinhirnhemisphäre ungleichnamige untere Olive ist ferner um sehr vieles umfangreicher als die gleichnamige: links sprang die untere Olive am unzerschnittenen Präparat halbkugelförmig wie das Corpus opticum der Vögel hervor, rechts zeigte sie nur eine mässig erhabene Anschwellung. Alles dieses wird durch die mikroskopische Untersuchung im vollem Umfange bestätigt. Diese ergiebt zudem, dass das rechte Corpus dentatu $\mathrm{m}$ viel grösser ist als clas linke, dass die rechtsseitigen Kleinhirnläppchen im Allgemeinen ausgebildeter sind als die linksseitigen. Der linke rothe Kern ist markfaserreich und grösser in seinen hinteren Partien, als der rechte. Da sich die Fasern des Bindearms beinahe vollständig kreuzen, kann es uns nicht verwundern, dass die mit dem rechten grösseren Bindearm in Verbindung stehenden Theile des linken rothen Kerns ebenfalls besser ausgebildet sind als die entsprechenden Theile des rechten rothen Kerns.

Nach den Resultaten der v. Gudden'schen Experimente, die in dem Vortrag "über die Verbindungsbabnen des kleinen Gehirns" (55. Versammlung deutscher Naturforscher in Eisenach. 1882. Tagebl. S. 303) mitgetheilt sind, war in unserem Falle bei den besprochenen Asymmetrien auch ein Kleinersein der hinteren Partie des rothen Kerns der Haube auf der rechten Seite von vornherein zu erwarten. Auch der Seitenstrang der unterhalb der linksseitigen Olive liegenden obersten Halsmarkpartien ist verbreitert und vergrössert. Es ist eben nicht nur die linke untere Olive grösser, sondern auch die sie umgebenden Theile des Nervensystems. Dass bei Ungleichheit der Kleinhirnhemisphären der Brückenarm im gleichnamigen, die Olive im ungleichnamigen Grössenverhältniss steht, ist schon 1831 von Demme in seiner Würzburger Inaugural- 
schrift: "Ueber die unglejche Grösse beider Hirnhällften" hetreff's sejnes ersten Falles beschrieben worden, stimmt aber nicht in einigen der anderen von ihm mitgetheilten Fälle. Gegenwärtig stehen die innigen Beziehungen zwischen Olive und gegenüberliegender Kleinhirnhemisphäre, die durch Faserzüge des Corpus restiforme vermittelt werden, ausser aller Frage. v. Monakow giebt in seiner Gehirnpathologie (S. 262) an, dass bei Zerstörung einer Kleinhirnhemisphäre der Bindearm nur damn entarte, wenn das Corpus dentatum mitzerstört wird, hiermit steht unser Fall in Analogie, indem wir bei einer mangelhafteren Entwicklung des linken Corpus dentatum eine geringere Ausbildung des linken Bindearms beobachten.

Unser fall ist noch in mehrfacher Weise complicirt, indem die Zwischenhirnpartien, deren Details zu entwirren mir noch nicht genïgend gelungen ist, Asymmetrien zu Ungunsten der linken, dio Mittelhirnpartien (hintere Vierhügel und laterale Schleife) wiederum zu Ungunsten der rechten Seite zeigen. Ob ein Zusammenhang zwischen den Asymmetrien des Zwischen- bezw. Mittelhirns und denjenigen der Kleinhirnhemisphären besteht, vermag ich nicht zu entscheiden. Auch eine Abhängigkeit der letzteren von der äusserst mangelhaften Entwicklung der Grosshirnrinde ist nicht zu erweisen. v. Gudden fand beim herangewachsenen Kaninchen das Kleinhirn und seine Verbindungen beiderseits normal, als er dem neugeborenen Thier eine Grosshirnhemisphäre entfernt hatte.

v. Monakow dagegen constatirte hei 6 Monate alten Hunden, bei denen am Tage der Geburt die rechte Grosshirnhemsphäre abgetragen war, ausser der bekannten Degeneration einen atrophischen Zustand des Bindearms und des Brückenarms, der in der Regel auch auf die gegenüberliegende Kleinhirnhemisphäre überging. (Gehirnpathologie. S. 257 . Wien 1897.) Bestände in unserem Fall eine Abhängigkeit der linksseitigen Kleinhirnhypoplasie von der Agenesie des Grosshirns, so wäro nicht $z u$ verstehen, warum nicht anch die rechte Kleinhirnhälfte in der Entwicklung zurückgeblieben wire.

Bei der Section der Bauchhöhle des hindes fiel Herrn Medicinalrath Dr. Schmorl die ausserordentliche Kleinheit der Nebennieren aut, die kaum $7 \mathrm{~mm}$ lang, nur $5 \mathrm{~mm}$ breit und $1 \mathrm{~mm}$ dick waren und lamentlich wenig Narksubstanz hatten. $\mathrm{Er}$ bereitete die umstehenden Aerzte sofort darauf ror, dass sich bei der späteren Eröffnung des Schädels voraussichtlich eine Missbildung am Grosshirn vorfinden würde. Warum konnte Herr Dr. Schmorl bei dem Befund starker Aplasie der Nebennieren - bei der Section eines 6 Tage alten Kindes finden sich die normalen Nebennieren $4 \mathrm{~cm}$ laug, $2 \mathrm{~cm}$ breit, $7,5 \mathrm{~mm}$ dick -- eine 
Missbildung des Grosshirns vorhersagen? Die Durchsicht eines Theils der einschlägigen Literatur lat mich belehrt, dass das gleichzeitigo Vorkommen dieser Anomalien schon seit Jahrhunderten festgestellt worden ist. Morgagni, Hewson, Renard, Cooper, Soemmering, Meckel u. A. haben Mangel oder Kleinheit der Nebennieren bei Hemicephalen constatirt. Dr. Joh. Heinr. Beck sehreibt in seiner Arbett "Ueber den ursprünglichen Hirnmangel" Nürnberg 1826, man habe die Kleinheit der Nebennieren als ein constantes Zeichen bei den Anencephalen bemerkt. Er ist der Meinung, dass in seinem Fall der Hydrocephalus die Ursache und die Kleinheit der Nebennieren die Folge sei, „indem bei dem Ueberhandnehmen des Transsudatums eine gänzlicho Hemmung der Absorptionsthätigkeit bemerkbar ist, mithin auch eine Verkümmerung aller jener Gebilde erfolgen muss, welche ibr vorzustehen scheinen". Noch in den nenesten Auflagen der Lehrbücher von Landois und von Birch-Hirschfeld ist des gleichzeitigen Vorkommens von Hemmungsbildungen im Hirn und Nebennierenaplasie gedacbt. Im Fötallehen muss ja die Nebenniere eine grosse Rolle spielen; lehrt doch die, Entwicklungsgeschichte, dass. die Nebenniere beim Säugethierembryo in der 8. Woche viel grösser ist als die Niere und beim Neugeborenen im Verbältniss zur Niere noch umfangreichere Dimensionen darbietet, als dies im späteren Leben der Fall ist. - Richard Magnus hat zu seiner Inauguraldissertation "Ueber das anatomische Verhalten der Nebennieren, der Thyreoidea und Thymus und des Sympathicus bei Hemicephalen“, Königsberg 1889 an 13 hemicephalischen Früchten der Königsberger anatomischen Anstalt Untersuchungen angestellt. Bei keinem der Hemicephalen wurde normale Grösse der Nebennieren oder ein völliges Fehlen derselben beobachtet; es waren sämmtliche Nebennieren kleiner als in normalen Früchten von entsprechender Grösse. Das Gewichtsverhältniss der Nebemnieren zu den Nieren wird nach seinen Untersuchungen um so ungünstiger für die Nebennieren, je näher die Früchte der Reife kommen. Die Grösse des Schädeldefectes ist ohne Einfluss auf den Grad der Atrophie der Nebennieren. Nach seinen und Weigert's Beobachtungen ist ferner die Grösse der Nebennierenatrophie keineswegs proportional dem Defecte des Centralnervensystems. Im Bereich des Nervus sympathicus konnte in keinem Falle eine Abweichung von dem gewöhnlichen Verhalten nachgewiesen werden. Bei einem der Fälle von C. Weigert (Hemicephalie und Aplasie der Nebennieren, Virchow's Archiv 1885. Bd, 100. S. 176) fehlte das Ganglion supremum des Sympathicus. Zunächst war Weigert geneigt, die Aplasie der Nebennieren anf das Fehlen dieses Ganglion zurückzuführen; bei einem nenen Fall von Hemicephalie jedoch, den er in Virchow's Archiv 
164 Dr. Georg Ilberg, Beschreibung des Centralnervensystems etc.

Band 103, Seite 204 in Jahre 1886 mittheilte, fand er das Ganglion cervicale supremum gut ausgebildet.

Ein Aufsatz von Boruttau in der am 21. September 1899 erschienenen Nummer der Deutschen medic. Wochenschrift enthält die Angabe, dass die Nebennieren einen Stoff herstellen, der die Blutüberfïlllung in den Muskeln und im Darm durch Vasoconstriction compensirt und so das Gehirn vor Anämie schützt. Man könnte auf Boruttau's Lehre gestützt daran denken, dass Kleinheit der Nebennieren diese hämodynamische Wirkung hindern und dass das gerade in der Entwicklung vor Anämie nicht geschützte Grosshirn sich in Folge dessen nur mangellaft ausbilden kann.

Die im Sectionsbericht beschriebene Lebernarbe, das vermehrte Gewicht der Milz, die constatirten Rundzellenberde, von denen namentlich der in den weichen Rückenmarkshäuten ein structurloses Centrum erkennen lässt, sichern die Diagnose der Syphílis.

Zum Schluss sei noch bemerkt, dass die beigefügten Photographien mit dem Zeis s sehen grossen mikrophotographischen Apparat angefertigt worden sind. Statt des Mikroskops wurde der Mikroplanar $1: 4,5 \mathrm{~F}=75 \mathrm{~mm}$, der vorn an die Camera angeschraubt war, benutzt. Der Cameraauszug betrug durchgängig $40 \mathrm{~cm}$. Das Präparat war auf einer Irisblendo festgeklemmt, die auf der optischen Bank stand. Die Beleuchtung erfolgte mit A u er'schem Gasglühlicht. Zwischen Lichtquelle und Präparat stand eine Planconvexlinse von $8 \mathrm{~cm}$ Durchmesser. Zwischen letzterer und dem Präparat befand sich der Cuvettenständer, der mit halb durch Wasser verdünntem Zettnow'schen Filter gefüllt war. Verwendet wurden Vogel-0bernetter'sche farbenempfindliche Trockenplatten aus der Fabrik von 0 . Perutz in München.

Meinem hochverehrten Herrn Director Geheimen Medicinalrath Dr. Weber bin ich für Beschaffung der Mittel und für freundliches Interesse an meiner Arbeit zu grösstem Danke rerpflichtet. 